\title{
A Conceptual Model for Blockchain-Based Agriculture Food Supply Chain System
}

\author{
Ibtisam Ehsan, ${ }^{1}$ Muhammad Irfan Khalid ${ }^{1},{ }^{1}$ Laura Ricci, ${ }^{2}$ Jawaid Iqbal, ${ }^{3}$ \\ Amerah Alabrah, ${ }^{4}$ Syed Sajid Ullah $\mathbb{D},{ }^{5}$ and Taha M. Alfakih $\mathbb{D}^{6}$ \\ ${ }^{1}$ Department of Information Technology, University of Sialkot, Sialkot, Pakistan \\ ${ }^{2}$ Department of Computer Science, University of Pisa, Pisa, Italy \\ ${ }^{3}$ Department of Software Engineering, Capital University of Science and Technology, Islamabad, Pakistan \\ ${ }^{4}$ Department of Information Systems, College of Computer and Information Sciences, King Saud University, \\ Riyadh 11543, Saudi Arabia \\ ${ }^{5}$ Department of Information and Communication Technology, University of Agder, N-4898 Grimstad, Norway \\ ${ }^{6}$ Faculty of Engineering and Information Technically, Aljanad University for Science and Technology, Taiz, Yemen
}

Correspondence should be addressed to Syed Sajid Ullah; syed.s.ullah@uia.no and Taha M. Alfakih; talfakih@just.edu.ye

Received 28 December 2021; Accepted 1 February 2022; Published 28 February 2022

Academic Editor: Punit Gupta

Copyright $(92022$ Ibtisam Ehsan et al. This is an open access article distributed under the Creative Commons Attribution License, which permits unrestricted use, distribution, and reproduction in any medium, provided the original work is properly cited.

In agriculture supply chain management, traceability is a crucial aspect to ensure food safety for increasing customer loyalty and satisfaction. Lack of quality assurance in centralized data storage makes us move towards a new approach based on a decentralized system in which transparency and quality assurance is guaranteed throughout the supply chain from producer to consumer. The current supply chain model has some disadvantages like a communication gap between the entities of the supply chain and no information about the travel history and origin of the product. The use of technology improves the communication and relation between various farmers and stakeholders. Blockchain technology acquires transparency and traceability in the supply chain, provides transaction records traceability, and enhances security for the whole supply chain. In this paper, we present a blockchainbased, fully decentralized traceability model that ensures the integrity and transparency of the system. This new model eliminated most of the disadvantages of the traditional supply chain. For the coordination of all transactions in the supply chain, we proposed a decentralized supply chain model along with a smart contract.

\section{Introduction}

Agriculture is a need for the majority of people worldwide to survive [1]. Improvements in agriculture productivity and quality, adequate marketing infrastructure, and assistance, and efficient food management are all prerequisites for agriculture growth [2]. Food safety appears to be an essential aspect that both producers and consumers are concerned about. Transparency in supply chains helps to improve the procedures engaged in manufacturing [3]. Traceability is also crucial as it allows us to determine the product's origin, including data such as the producer, harvesting and production dates, and so on. To meet the growing demands, the agricultural system has to be vastly improved [4]. To address the complicated agricultural issues, advanced technologies are being developed. Blockchain is the most recent addition to these technologies. A cryptographic hash is the base of blockchain technology. It is a transaction ledger system that is decentralized and immutable [5]. This guarantees that the user's transactions and identity can never be affected. If a forged transaction takes place, the decentralized mining mechanism will prevent it from entering the encrypted chain [6]. The supply chain logistics industry is the most visible implementation of blockchain technology [7]. In the field of logistics, blockchain moves ahead with a lot of options regarding the shipment of data. Every product or item can be 
tracked, which helps in precautions for any possible delay in shipment [8]. Internet of things can be utilized with blockchain to track the supply of perishable goods. Blockchain has various trading applications as well. The transaction in agriculture supply chain management includes the data about raw material and quantity etc. and blockchain technology can maintain various crop insurance schemes with the help of proof of records for a claim during the loss of crop in any case. The use of smart contracts is helpful for settling transactions and eliminates intervene of any third party, and this could be considered the main advantage of blockchain technology [9].

\section{Literature Review}

In this particular section, we review the work related to blockchain in the agriculture supply chain found in the literature. Blockchain has gained massive popularity in the banking and finance industry, but it is growing steadily in agriculture. In [10], the authors proposed a hazard analysis and critical control points based agriculture food supply chain traceability model with the collaboration of blockchain and IoT. A use case of tracking a product from producer to consumer is implemented through hyper-ledger, and Ethereum is presented in [11]. Moreover, the authors introduced a traceability solution for the food value chain. The authors discussed how to apply blockchain technology in the agriculture food supply chain and also raise the trust, security, and integrity issues in [12]. In [13], the authors reviewed the Agri-ICT concept in blockchain and presented an improved model of ICT in the agriculture blockchain. For increasing efficiency in smart contracts and DLT, an approach is introduced in [14]. Furthermore, the authors highlighted the challenges and barriers while adopting blockchain technology in agriculture. In [15], researchers introduced an efficient blockchain agriculture food-management supply chain with smart contracts. Potential risks and challenges while adopting blockchain in the food supply chain are discussed in [16]. In [17], the authors proposed a new blockchain approach that is based on an IPBFT algorithm to optimize trading for food supply chain buyers. In [18], researchers presented an approach to measure the grain quality using blockchain smart contract. Authors explored in [19] how to blockchain-based systems promote value transfer in small-scale agricultural farms. To increase transparency and automate the process of blockchain in agriculture, authors in [20] introduced an advanced prototype. The authors studied challenges in the implementation of blockchain in the dairy industry in [21]; moreover, they introduced a hyper-ledger-based solution for blockchainbased traceability. As seen by the linked study, there is a strong trend toward using blockchain technology in food and agricultural supply chains to improve information security, transparency, and verification of different criteria [22]. The literature demonstrates how blockchain and smart contracts can provide supply chains with an efficient, trustworthy, safe, and decentralized trace and track. Table 1 describes the proposed methods and their attributes by various researchers.

\section{Challenges}

(i) There is no way to change or update data in a blockchain if, at any step, someone makes a mistake. The immutability of blockchain is one of the major advantages. However, as opposed to traditional database systems, blockchains are hard to amend or manipulate.

(ii) A verified transaction cannot be altered by security schemes.

(iii) Using smart contracts, the system can be controlled and the steps can be automated. Smart contracts cannot be modified after they are deployed.

(iv) The blockchain environment will require some money during its initial setup.

(v) It is possible for IoT devices to be hacked.

(vi) The acquisition of data requires IoT devices. Data collection can be affected if devices are damaged.

\section{Traditional and Centralized Supply Chain}

As shown in Figure 1, supply chains have a traditional structure. A central database containing data regarding all processes is created by using this approach. An administrator manages the database. Several limitations apply to this approach. This system uses a server to manage the database. Therefore, if that server fails, the entire system will go down. An administrator who is dishonest could change the data without the stakeholder's knowledge [4]. Those manipulations are inadmissible to trackback. Thus, this centralized approach is opaque and untraceable as well. Among the major challenges of the traditional supply chain ecosystem are traceability of products, transparency of stakeholders, and trust in collaborative systems. In the traditional approach, there are a lot of intermediaries, causing trust problems and performance problems [7]. Various supply chain entities include farmers, distributors, retailers, etc. Consequently, any outbreak involving food products will be extremely difficult to trace [10]. It is essential to examine the functional impact, social impact, and economic impact of emerging technologies in the supply chain ecosystem. Furthermore, the traditional supply chain ecosystem is highly centralized. This leads to trust issues when multiple organizations collaborate. A centralized process makes it easy to manipulate data without the knowledge of other stakeholders. Any carelessness in the food supply chain may put the lives or health of people at risk [8]. This is a big concern when it comes to traceability. Trust issues within the supply chain can result in significant losses for companies. Companies put the utmost effort into creating trust among consumers. Providing access to data while protecting it from being altered by others should resolve these issues. By utilizing emerging technologies in the supply chain, we can resolve these issues. With blockchain technology, supply chain performance can be improved, and issues can be eliminated. Furthermore, it has some features that make it useful for addressing supply chain concerns beyond its use of distributed ledger technology. As a result of its immutability 
TABLE 1: Literature proposed methods and their attributes.

\begin{tabular}{lcccccccc}
\hline Papers & $\begin{array}{c}\text { Provide system } \\
\text { implementation }\end{array}$ & Traceability & $\begin{array}{c}\text { Control over the } \\
\text { system (smart } \\
\text { contract) }\end{array}$ & $\begin{array}{c}\text { Customer } \\
\text { decision-making } \\
\text { made easier }\end{array}$ & $\begin{array}{c}\text { Getting } \\
\text { real-time } \\
\text { data }\end{array}$ & $\begin{array}{c}\text { Fraud } \\
\text { reduction }\end{array}$ & $\begin{array}{c}\text { Eliminating } \\
\text { third parties }\end{array}$ & $\begin{array}{c}\text { Price } \\
\text { transparency }\end{array}$ \\
\hline$[23]$ & No & Yes & Yes & Yes & Yes & Yes & Yes & No \\
{$[24]$} & Yes & Yes & Yes & Yes & No & No & Yes & No \\
{$[25]$} & No & Yes & No & Yes & Yes & Yes & Yes & No \\
{$[17]$} & No & Yes & No & No & Yes & Yes & Yes & No \\
{$[26]$} & Yes & No & Yes & No & Yes & Yes & No & No \\
{$[10]$} & Yes & Yes & Yes & No & No & Yes & Yes & No \\
{$[1]$} & No & Yes & Yes & No & Yes & Yes & Yes & Yes \\
{$[27]$} & No & Yes & Yes & No & No & No & Yes & No \\
{$[28]$} & Yes & Yes & Yes & Yes & No & Yes & Yes & No \\
{$[12]$} & Yes & Yes & Yes & No & No & Yes & Yes & No \\
\hline
\end{tabular}
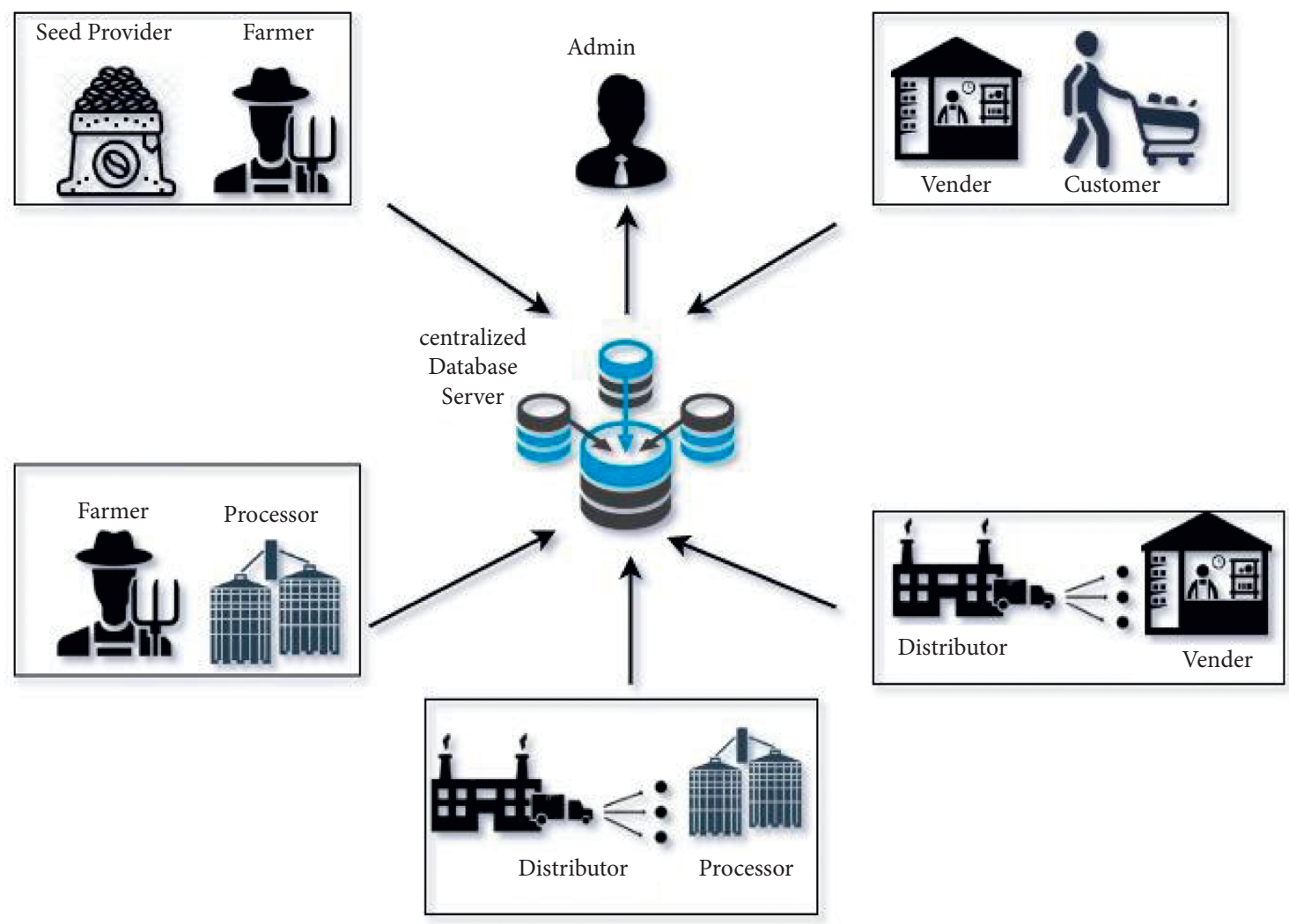

Figure 1: Centralized food supply chain.

and distributed nature, it provides a secure and reliable record that cannot be altered or altered. Food supply chain ecosystems can be improved by transparency and the use of emerging technologies [14].

\section{Blockchain in the Agri-Food Supply Chain}

Many difficulties have plagued agriculture and food (agrifood) supply chains, including a lack of traceability, poor visibility, and inefficiency [27]. These challenges have a direct and considerable impact on management efforts to ensure agri-food production compliance, enhance food safety and quality, reduce food waste, and decrease supply chain operation expenditures [29]. The advancement of a traditional supply chain becomes imperative in the case of unexpected growth of a product's demand [30]. Moreover, customer satisfaction can be improved with the help of supply chain management. A supply chain comprises operations such as product flow, information, and product travel history. Figure 1 portrays a traditional food supply chain that includes producers, suppliers, manufactures, distributers, and retailers working in a chain to deliver products from producer to consumer. Traditional supply chains based on centralized systems lacks traceability, transparency resulting in data loss, data tempering, and security threats. There are the following drawbacks of a traditional supply chain: 
(i) No traceability and transparency.

(ii) No details of product origin.

(iii) No food safety is assured at any stage.

(iv) No record of any transaction in the whole supply chain.

The upper stated issues can be solved by blockchain technology; over distributed networks, it acts as a public ledger and overcomes information maintenance issues like verification and validation. Blockchain technology provides security, maintains temper proof record, avoids any kind of the third party of middle man in transactions, helps to reduce the overall cost of trans-action, and improves the product quality. The cryptographic approach followed here develops user confidence, resulting in increasing the product's demand [31]. Cryptocurrency-related encryption methods assist in the validation and verification of users and new blocks; that is why each block in the blockchain network contains the details of the transaction. The chain contains a ledger from the beginning to the creation of a new genesis block [32]. Each block has a reference to the preceding block due to a hash value. The peer-to-peer network assists in the verification of new transactions and users [33]. Among the emerging technologies, blockchain technology is likely to have a significant impact on many areas of collaboration. By using distributed ledger technology, entities can communicate without a middleman in a peer-to-peer network. By virtue of its numerous features, it promotes trust and transparency in cooperative environments. The decentralized nature of its operation means that it is not controlled by a single party or entity. A consensus refers to an agreement reached between all parties regarding how to carry out a transaction. This feature permits the traceability of any transaction. Whenever a transaction is made, the distributed ledger is updated so that all nodes can see it. One of the most important features of immutability is that it makes it impossible to tamper with [34]. Unlike traditional databases, the distributed ledger cannot be modified or deleted once it has been written. Smart contracts can also be implemented on the distributed ledger. These are computer programs used to specify the logic of a contract between two or more parties. After the contract is executed, certain conditions must be satisfied.

5.1. Provenance Tracking. Blockchain technology can be useful to resolve discrepancies in transactions when historical information is required. The blockchain-based solution can track the provenance of transactions. Transactions can be tracked from when they were initiated.

5.2. Transparent Procurement. A company looks for a middleman every time it is in the procurement process. It is almost impossible to track the exact volume or quantity between partnership firms, subsidiaries, etc., using the traditional approach. With the blockchain, this process can be automated. With the blockchain, virtually all transactions are visible and continually updated. Companies can check their orders by using distributed ledgers. Auditing employees are usually hired just for the auditing process [26]. As a result of blockchain, auditing will become much easier and faster without involving so many people.

5.3. Transacting Immutably. Authorized nodes can execute multiple transactions. Attackers cannot delete or modify the transactions. Transactions in the blockchain cannot be altered or deleted once they are recorded in the decentralized ledger since they are immutable [5]. It is impossible to delete or update transactions that have already been executed, not even the administrator. As part of blockchain technology, the hash function is used, which means modifying the data can affect the hash.

5.4. No Rogue Frauds. There is a decentralized ledger shared by all connected nodes on the blockchain. Each node's ledger reflects these transactions. Rogues who try to execute transactions for their own benefit are doomed to failure [21]. Each transaction must be approved by all stakeholders due to the consensus feature of blockchain. Table 2 illustrates the major challenges that exists with the agri-food supply chain system, apart from that all those challenges which currently opted supply chain process in the agri-food.

\section{Use of Smart Contracts for Blockchain-Based Agriculture Supply Chain}

The blockchain allows us to eliminate intermediaries, but the promises and trust boundaries between the contributing parties typically require something called a smart contract. In the same way that traditional contracts regulate trust between the parties, smart contracts provide organizational terms and conditions that govern trust within the scope of the contract. A smart contract is only different because it is coded in a programming language [7]. Using controlled coding, the rules, terms, and conditions reflected in the agreement are implemented exactly as agreed by all parties. A smart contract concept has existed since the 1980s, but all it lacked was the removal of intermediaries. Smart contracts were introduced in 1996 by Nick Szabo [35]. A smart contract embeds the contractual terms within a combination of hardware and software, making it difficult for them to be breached, and making them cost-prohibitive. As such, smart contracts increase safety by reducing attacks. Ethereum blockchain popularized the notion of smart contracts and its implementation in real life in 2016. The Ethereum network combines a decentralized Turing-complete blockchain with a smart contract environment and integration tools. Figure 1 shows the steps involved in building a smart contract. In other words, a smart contract automates processes in blockchain technology. By storing the contract within the blockchain, we can potentially use blockchain in other realworld situations. To automate the steps involved in the system, the authors in [18] use smart contracts as their core technology. Real-time tracking of products in a supply chain and a comprehensive view of the process are both part of the automation. Using a smart contract, [7] incorporates 
TABLE 2: Challenges and opportunities while adopting block chain in agriculture.

Opportunities and potential benefits

Food-borne disease risks are reduced when items

are of higher quality

User friendly for farmers

Fewer number of frauds due to transparent transactions

Financial transaction facilitation for every entity in the supply chain

Enhanced sustainability and reduction of waste

A valuable platform for reducing emissions Pricing is more equitable across the whole value chain

Purchase decisions are made by well-informed consumers

Consumers are well informed about what they are purchasing

Less reliance on intermediates and third parties

Insurance policies and financial aids for rural area farmers

Traceability and transparency in value chains
Challenges and barriers

Platforms for education and training are limited

Market fluctuations and ambiguity

Small businesses lack of competence

New users may be unable to access marketplaces due to a lack of information infrastructure

As the technology ahead forms trigonal methods, SMEs have various issues and difficulties while adopting

Understanding issues among policymakers and technical support staff

Requirements of IoT/computing equipment

Digital gap between developing and developed countries

Cryptocurrencies market share is dwindling, and there is a lot of volatility (reputation issues)

Open technological questions and scalability problems for example transactions latency

Limited flexibility in design decisions [19]

Some food quality factors, particularly environmental indicators, cannot be assessed using objective analytical methods industrial spare parts traceability research to implement the necessary functions, modifiers, and events to implement the logical flow mechanism to automate the entire process. By securing contracts within the blockchain, smart contracts can satisfy the fundamental need for trust between parties. The paper [2] proposes implementing an IoT-based automobile insurance ecosystem known as CAIPY, which implements step-by-step processes and communicates with tamper-proof IoT devices in order to monitor a car's condition. Smart contracts can be used for intellectual property rights management. Paper [36] presents BMCProtector, a music copyright management platform using blockchain and smart contracts. From song creation until royalty distribution, their smart contract system implements all the necessary functionality. It is nearly impossible to alter a smart contract that has been distributed within a blockchain because they are distributed inside the block chain, so you need to deploy them within a blockchain environment for maximum security. When coding smart contracts, you will frequently come across terms like attribute, function, event, and modifier. Here is an explanation of these terms.

Attribute: a variable that holds a value in memory is an attribute. Various primitive data types are supported in solidity: integers, chars, strings, doubles, and mappings, addresses, and enumerators.

Function: in a system, functions represent mechanisms and tasks. If a function is called, the task it contains will be executed.

Modifiers: actors or components have access power through modifiers. Although the contract owner has ultimate control over modifications, other actors or components can be granted some specific rights to modify or gain access.
Event: a blockchain transaction log stores anything that happens as part of an event. In the transaction logs of the blockchain, in response to an event taking place or being emitted, any argument that is passed along with that event gets recorded. This mechanism allows for the subsequent retrieval of historical information about the system. The system is auditable through this mechanism.

Smart contracts are computer programs that run when certain conditions are met and recorded on a blockchain [15]. They are often utilized to automate the execution of a contract so that all parties are instantly in-formed of the results, without the need for any middlemen or time waste. Traditional contracts are no longer efficient for blockchain technology [15]. The traditional supply chain also contains a huge amount of paperwork and documents which is not a good approach for tracking and records proofs. Smart contracts are automatically executed and triggered when preset criteria are fulfilled, can assist to address these drawbacks of transparency, efficiency, security, and tracking, and eliminate the role of a mediator [18]. These auto-executed code-based contracts enable agreed-upon activities (such as payments) to occur quickly upon the completion of the terms of the contract. This is a major function that differentiates blockchain from Ethereum. For example, when a client verifies their shipment, according to the instructions a smart contract will transfer money to the carrier. Smart contracts are unique in that they allow you to write code that executes itself without the need for a third party, which helps to save a lot of money, time, and effort, also no chance of errors or frauds. In comparison to a traditional contract, a smart agreement between two parties participating in a transaction holds each participant responsible for their participation in the transaction and also ensures that 
the contract is implemented. Smart contracts increase a supply chain's transparency, traceability, and efficacy, allowing it to be more flexible in establishing connections between partners. A unique address is assigned to every smart contract. This address never changes one of the contracts deployed in the blockchain. User transactions can only send to a contract address. Every consensus node in the network will execute the transaction to achieve a consensus on its output. The two forms of smart contracts are deterministic and non-deterministic smart contracts [29]. A deterministic smart contract executes without the need for any information from a third party. A non-deterministic smart contract relies on third-party data (database). A smart contract works by following simple "if/when ... then ..." statements which are written into the blockchain code.

An action is executed by a network of computers when certain conditions have been met and verified. A blockchain is then created to record the transaction. Parties who have already been granted permission are the only ones who can see the results of a transaction unless permission is granted [37]. The participants in a smart contract can specify as many conditions as necessary to ensure a successful outcome. By defining how transactions and their data will be represented on the blockchain, establishing the "if/when...then... rules" that will govern the transactions, exploring all alternative possibilities, and establishing the dispute resolution framework, participants are in the process of setting the conditions as shown in Figure 2. Supply chain management is expected to benefit from blockchain technology to reduce the number of coordination challenges [38]. Smart contracts can handle multiple transactions between parties, which reduces complexity, enables greater transparency across the supply chain, and enhances the trust-less verification process. The supply chain will be streamlined and made more flexible, and stronger partnerships will be fostered [39]. Considering the above discussion of the use of blockchain and smart contract in various fields and use cases, it is quite clear that the combination of blockchain and smart contract results in an automated, highly secure, and ingenious system. Rather than storing and tracking data in a blockchain, smart contracts implement the business logic and control access to the data.

\section{Benefits of Smart Contract over the Traditional Supply Chain}

7.1. Transparency. Through smart contracts, the provenance of goods can be recorded, enhancing supply chain transparency. The blockchain stores information such as the date, location, and quality, which are helpful in verifying a product's origin. Consumers will have more confidence that they are purchasing good products, and manufacturers will have the assurance that their raw material comes from a reliable source [40]. Smart contracts can also be used to enable transparent credentialing among supply chain partners by creating and storing digital forms of identification. With this system, parties can easily verify that other parties have the requisite certifications to be able to do their duties [41]. Blockchain technology can also be used to manage reputations and reliability.
7.2. Traceability. Using smart contracts, traceable inventory can be tracked from its raw material source to its delivery to its end-user, which can improve supply chain traceability. A serial number, RFID tag, or smart sensor can be used to accomplish this. In addition to location and environmental data, smart sensors can provide information about product quality (especially for perishable goods). The ability to make better and faster decisions will be improved with real-time information and updates about product status. In this case, it is easier to activate a reserve batch of goods midway through the supply chain process rather than to wait until the bad batch arrives before making a decision. As a result, delays can be reduced, and the supply chain can remain agile [35]. Natural disasters, factory strikes, and delivery accidents will also be dealt with well by the organizations. With the increase of product competition, ensuring continuity of supply can significantly enhance a brand's image among consumers.

7.3. Efficiency. A smart contract can improve the efficiency of the supply chain from both an operational and cost perspective. Using distributed ledgers to perform smart contracts simplifies multi-party supply chains, improving process efficiency. Because smart contracts execute themselves automatically, they can automatically execute "contractual rights and obligations, including payment and delivery terms" [42]. Reduced processing time and work are the results of reducing paperwork. Cost reduction is another way to enhance efficiency. As contractual agreements are executed using trusted computer code that can easily be customized, fewer physical documents need to be created and maintained by each party's purchasing, accounting, or legal departments. By eliminating physical records, a great deal of manual work can be reduced [43].

\section{Process of Blockchain Implication in Agriculture}

Consumer-to-provider solutions provide a database including an efficient structure as well as a public ledger that holds digital data about items, persons, and events that can be viewed or examined by a large number of people in the blockchain [44].

Using blockchain technology in supply chain management, we can overcome issues like the following:

(i) Overall management of the system.

(ii) System errors.

(iii) Product delay.

(iv) Transparency.

(v) Traceability.

(vi) Improving communication between all entities in the supply chain.

(vii) Increasing the trust between consumer and supplier.

Improvement in the supply chain is needed to tackle the changing and increasing demand of customers. Also, we can normalize the use of blockchain in the food supply chain to 


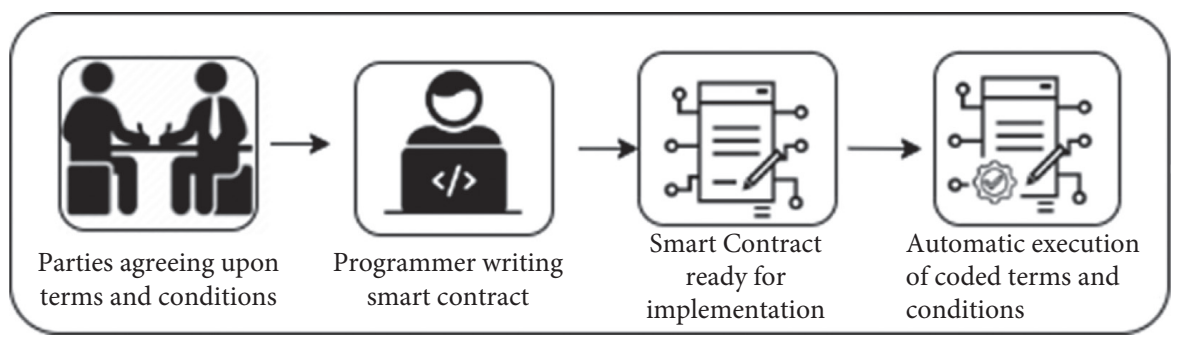

FIgURE 2: Smart contract building steps.

make a better marketing environment. The food product's data, such as its harvesting date and price, is uploaded by the supplier and then an RFID chip is embedded in the product as shown in Figure 3 [5]. These tags consist of an antenna and a microchip. Special printers are used to print identifying information on tags. The information on tags can be utilized for a variety of purposes. When RFID scanners scan a product, information from the tag is read, which might include essential information for preserving the item and managing the supply chain, such as the following:

(i) Components of product.

(ii) Product ID number.

(iii) Location history.

(iv) Order status.

(v) A serial number of an individual product.

Figure 3 illustrates how RFID receiver can be used to update and send this information and the data is not restricted to only containing serial numbers and ID. As the goods pass through warehouses and vehicles, the information provided by RFID will be linked to the system automatically tracking shipping and stock positions. By incorporating RFID into these systems, it is possible to verify the correct items and quality of products. Product information could be tracked throughout the whole shipping process and storage with the collaboration or IOT that increases accountability and accuracy. Supply chain networks fully utilizing RFID can detect the location of the goods, allowing theft and other unlawful actions to be found and punished instantly. After tagging by the supplier, the manufacturer gathers product information and adds a QR code to the package [41]. The product then moves towards the distributor, who is automatically notified of the arrival of food goods. Then, based on completely accessible data on customers, like delivery dates, and other user information, distributors select a suitable 3PL (Third Party Logistics) [45]. The origin and destination of food goods are then communicated to 3PL. It optimizes network flows flexibly. The product now transferred to the retailer uses machine intelligence to anticipate sales and also provides a mobile application to customers. The product is now ready for sale. Product information remains the same throughout the chain [17]. The store provides full transparency on delivery time. Each company now scans the RFID at each step of the manufacturing process and updates the information on the blocks in the cloud using a mobile app [6]. As a result, the cloud plays an important role in storing blocks. The app or website is used for verification, validation, and transactions, among other things [12]. A communication plat-form is

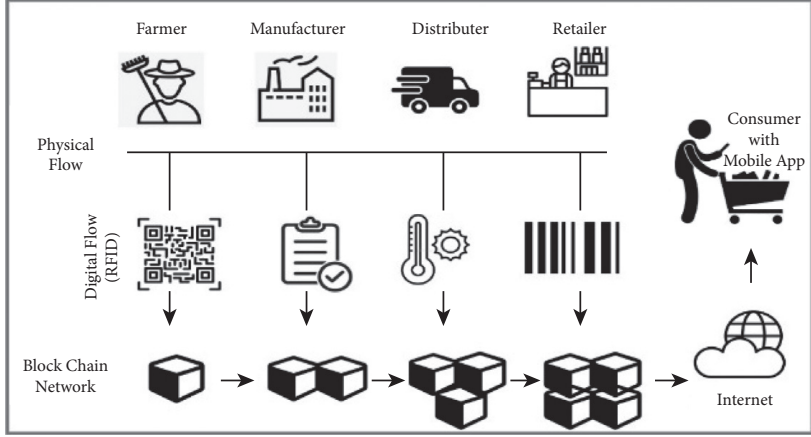

Figure 3: Traditional food supply chain.

provided through a website and a mobile app. When the genesis block is formed, the information is saved in it, and the very first transaction is carried out, and the blockchain technology begins to operate. Customers may access product data such as origin, aging, duration, and expiry by scanning the QR code using an app.

\section{Blockchain-Based Proposed Model for Agriculture Supply Chain Using Smart Contracts}

In this paper, a new model for tracking and traceability is presented. Block chain smart contract is involved in this proposed model to coordinate traceability of food in the agriculture supply chain. The implementation of this model improves the traditional blockchain-based supply chain. There are 4 layers in this model. In the first layer, the producer agent manages all the operations that come in their domain like buying materials and selling products. The next layer deals with processor agents who process the products like sorting, packaging, and processing. In the transport layer, all the tasks regarding transport between whole supply chains are managed by transport agents. In the next layer, the retailer agent purchases a product from the processor agent and sells it further to customers. All the entities in the whole supply chain are interconnected in a decentralized blockchain with a smart contract. And every transaction in the whole system can be traced through blockchain network. Everyone in the whole supply chain can trace the product as portrayed in Figure 4.

A consumer can check the origin and processing of the product. This new supply chain model enables the agricultural industry to gigantically grow [24]. The use of 
blockchain enables the consumer to trace all the products from origin to delivery. The main benefit of this model is the confidence of the final consumer that will increase the sales a lot. Figure 5 shows the sequence diagram for the proposed model.

\section{Outcomes of the Proposed Model}

After having examined enough literature survey and experiments from numerous researchers, we proposed our conceptual model that has components that are being used in the manual/current agri-food supply chain processes and the other which would be a blockchain-based model. We have constructed a detailed Table 3 that explains the possible outcomes of the blockchain-based system and how this system can ensure transparency, traceability, security, and immutability in the entire agri-food supply chain process.

\section{System Flow Analysis}

Consider the supply of rice from the farmer to the consumer. The farmer first purchases seeds from seeds suppliers. The seeds are grown on the farmer's farm. After harvesting the crops, he uploads the detail document to the network, which contains information about the seeds, the seed suppliers, and the crops. The blockchain will record the transactions relating to this document. After reviewing all the details of a farmer's seeds and crops, the rice processor can place a purchase order directly with him. Unprocessed rice is sent to the processor with a document containing details about the processing. After the processor receives the order, the distributor oversees the contract. The distributor then inspects the retailer's buy order. Upon completion, the distributor ships the orders to the retailer [46]. A document with the shipment information is uploaded by the distributor. Upon receiving the rice from the distributor, retailers sell it to consumers. All information about the rice, from its starting date to its end process, can be viewed by the customer. Smart contracts permit communication between two entities. Proof of authority is established using a consensus mechanism in this model. The consensus determines which nodes are permitted to validate transactions. For example, an entity sending the data to the validator node for validation will be notified by the validator node [43]. A notification will be sent to the validator node once the transaction is complete. A transaction is approved by them if it is deemed legitimate. When a validator finds that a transaction is not authentic, it can be declined. The information flow of whole system is presented in Figure 6.

Apart from that, the diagram of the entity relationships is depicted in Figure 7. These depictions are for the reference of our system's work flow and events occurring at any stage of the whole process.

\section{Contribution}

In this paper, we have proposed a permissioned blockchain model that is essentially validated with the Ethereum blockchain. The blockchain supply chain model is full

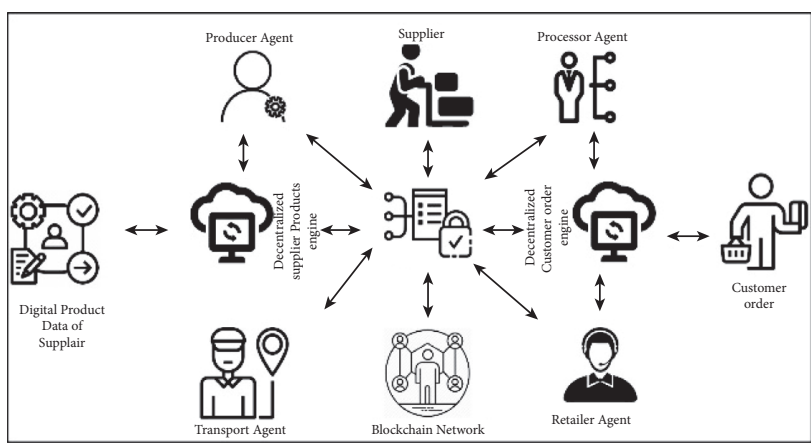

FIGURE 4: Decentralized smart contract-based supply chain.

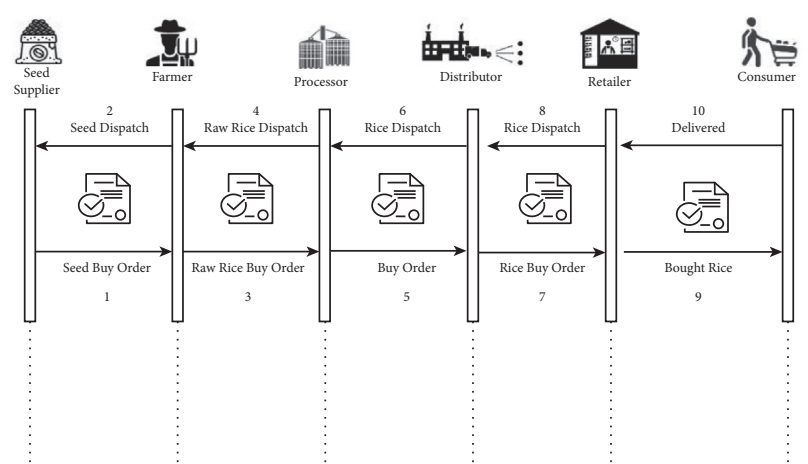

Figure 5: Sequence diagram of food supply chain.

decentralized model, in which we have introduced certain concepts that are vital for the effective process of supply chain using novel technologies like blockchain.

\section{Validation of the Model by Ethereum Blockchain Smart Contact}

Although we have studied and researched theoretical aspects of using smart contracts, still we are giving a testing and validation of the proposed model. Validation can also be performed by having an experiment with those stake holders who are currently using these systems. But here we are going to have some smart-contract-based technical validations. In order to give some sort of validation for our proposed model, we have used Ethereum blockchain and wrote a simple smart contract which has shown the possibility of using blockchain technology and its relevant tools for the innovation of the current agri-food supply chain process; our validation helps to identify the potential of blockchain technology. Below are a few shots of the smart contract and how that smart contact got compiled. Figure 8 shows the first part of our smart contract that we wrote for the validation of our proposed model.

Figure 9 depicts the smart contract for the proposed activity of supply chain process of agri-food process.

Figure 10 is again a representation the functions declarations and their calls for the specified events.

Figure 11 is for the reports that would be the ultimate source of transparency and through which we can have a detailed track of our supply chain procedure. Figure 12 is the last part of our smart contract. 
TABLE 3: Outcomes of the proposed blockchain-based agri-food supply chain system.

\begin{tabular}{|c|c|c|}
\hline Attributes & BC-based proposed system & Traditional method \\
\hline Immutability & The information in a transaction cannot be changed even by the admin & $\begin{array}{l}\text { Information can be easily manipulated by the } \\
\text { admin }\end{array}$ \\
\hline Consensus & Stakeholder agreement is taken into account & No consensus available \\
\hline Provenance & Transaction histories are available & No history, no information record \\
\hline Structure & Fully decentralized & Centralized \\
\hline Trust & Increasing trust in a collaborative environment & Centralized approaches impose trust issues \\
\hline Storage & Distributed storage & Centralized \\
\hline
\end{tabular}

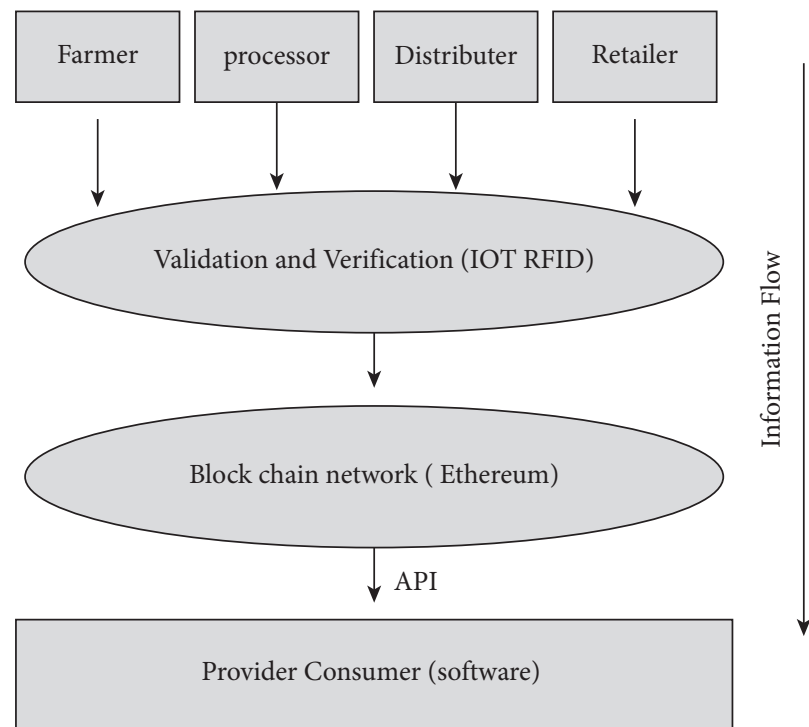

FIGURE 6: Information flow throughout the system.

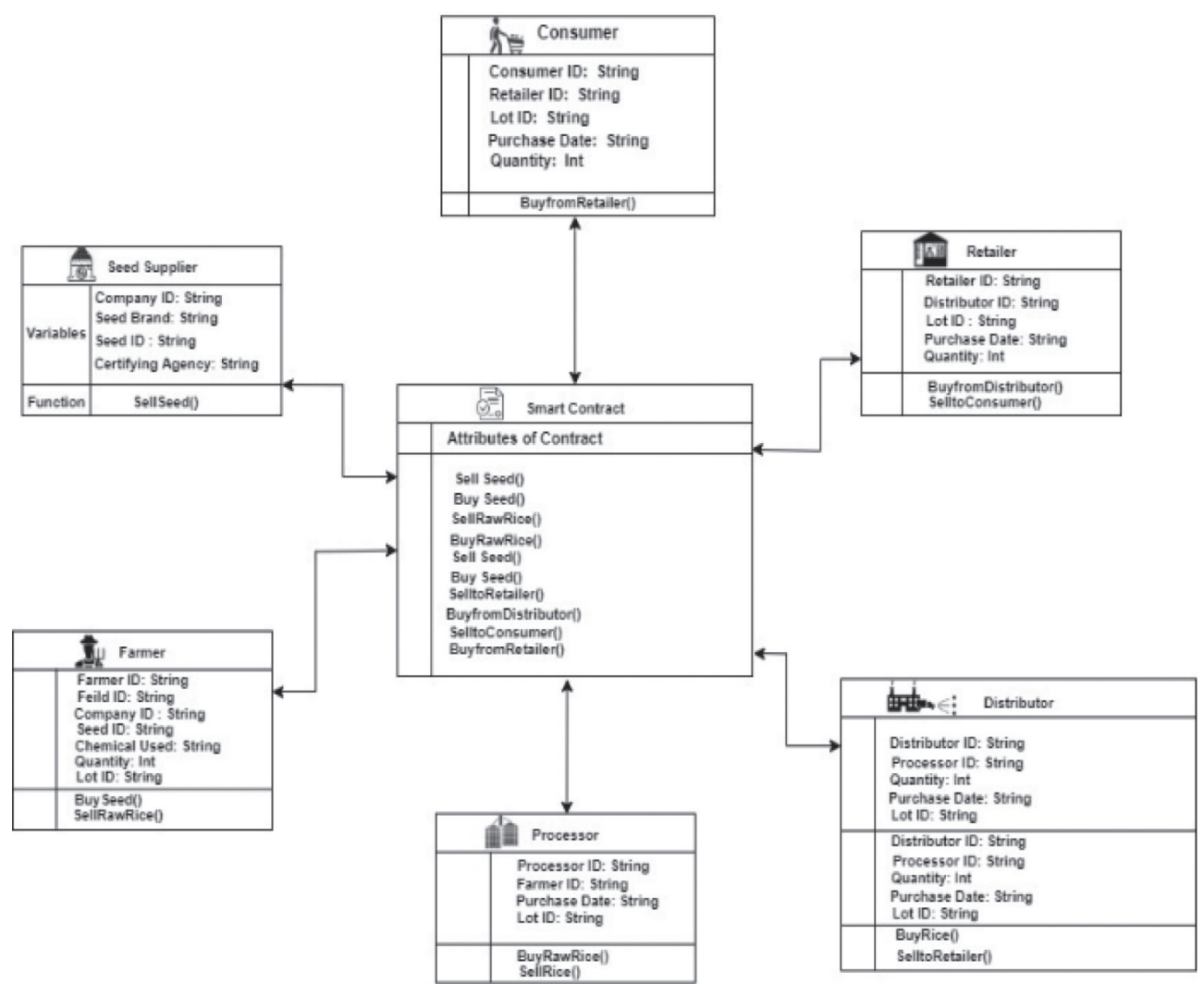

FIGURE 7: Entity relationship diagram of proposed model. 


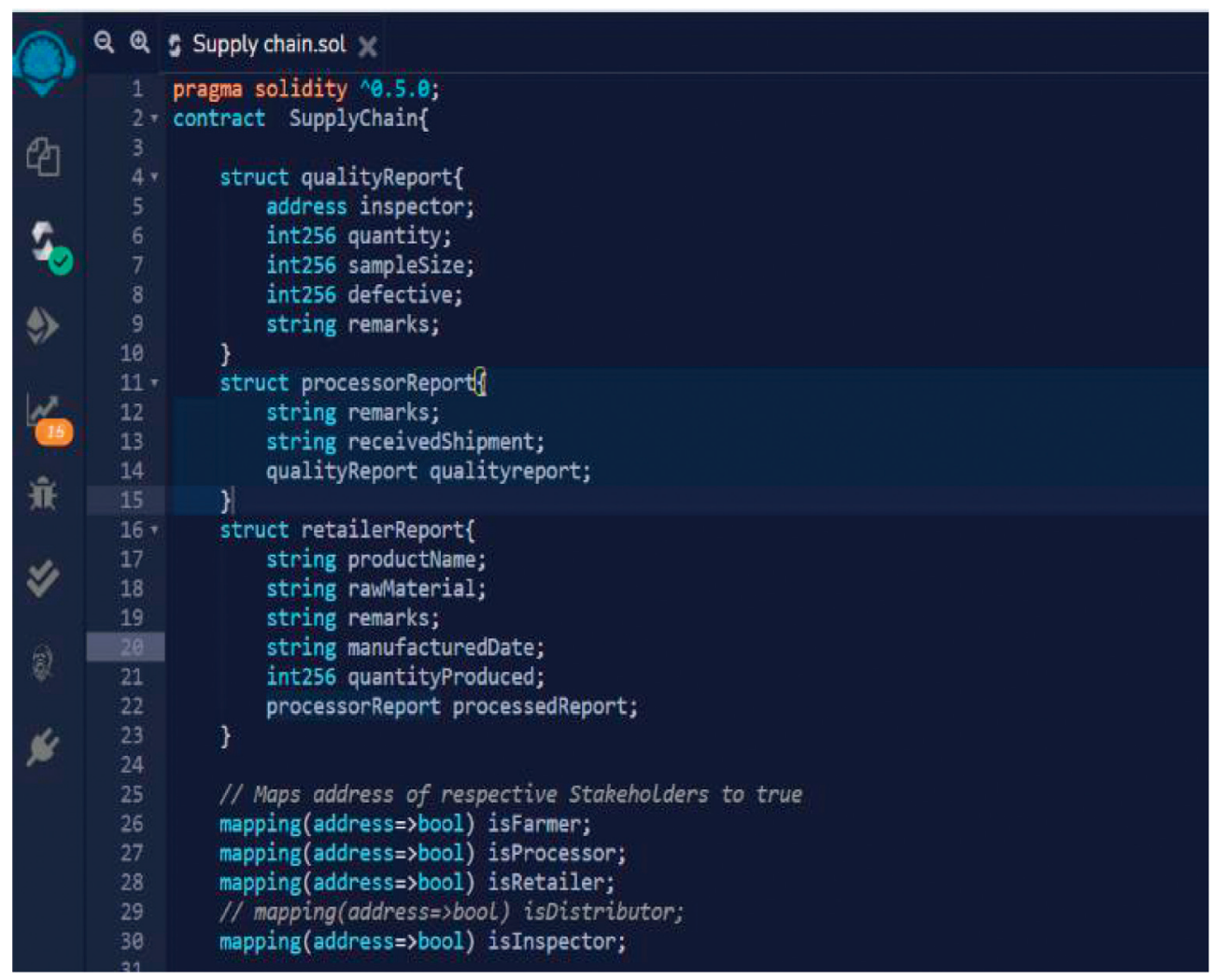

FIgURE 8: Part 1 of the smart contract.

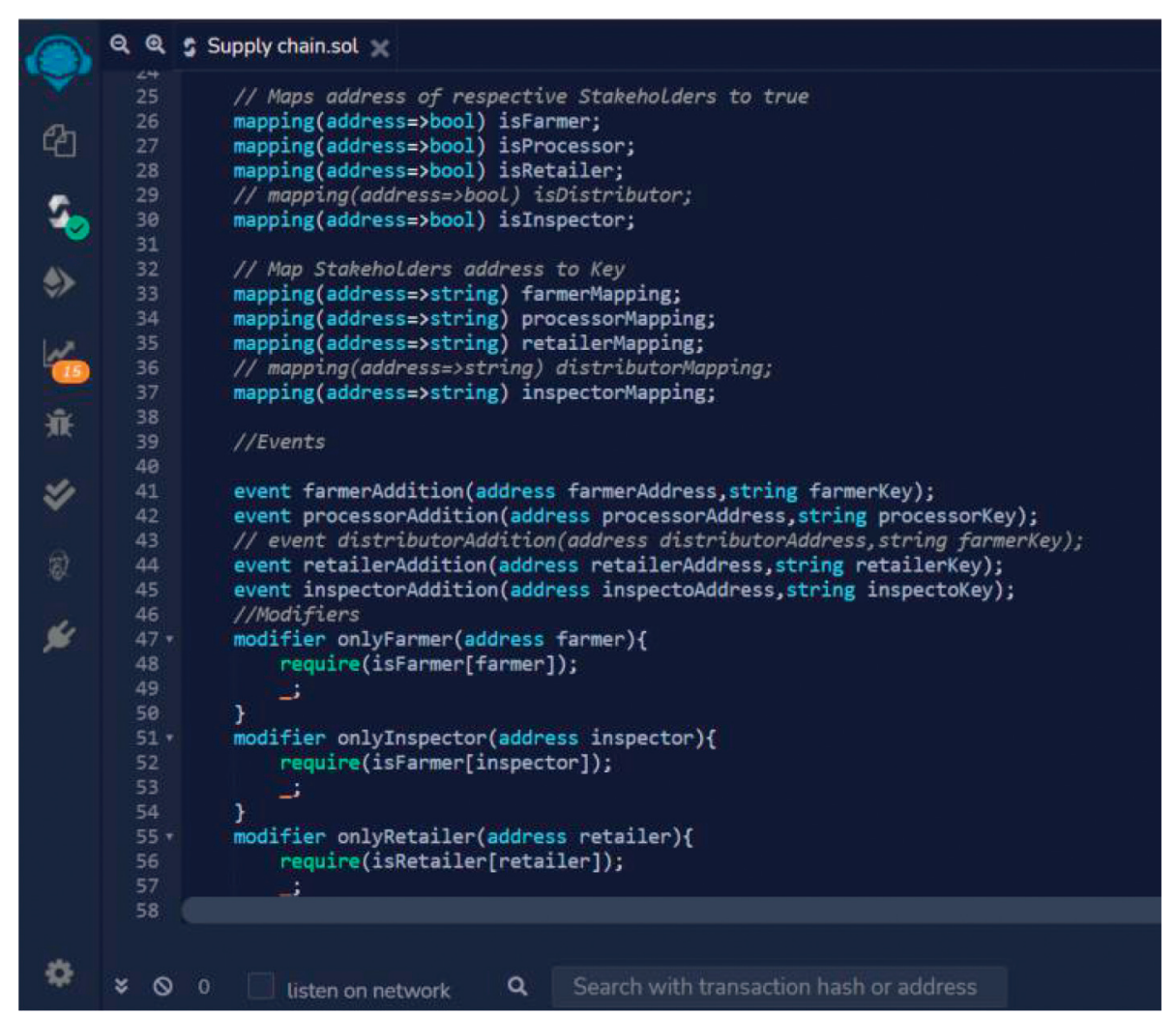

Figure 9: Part 2 of the smart contract. 


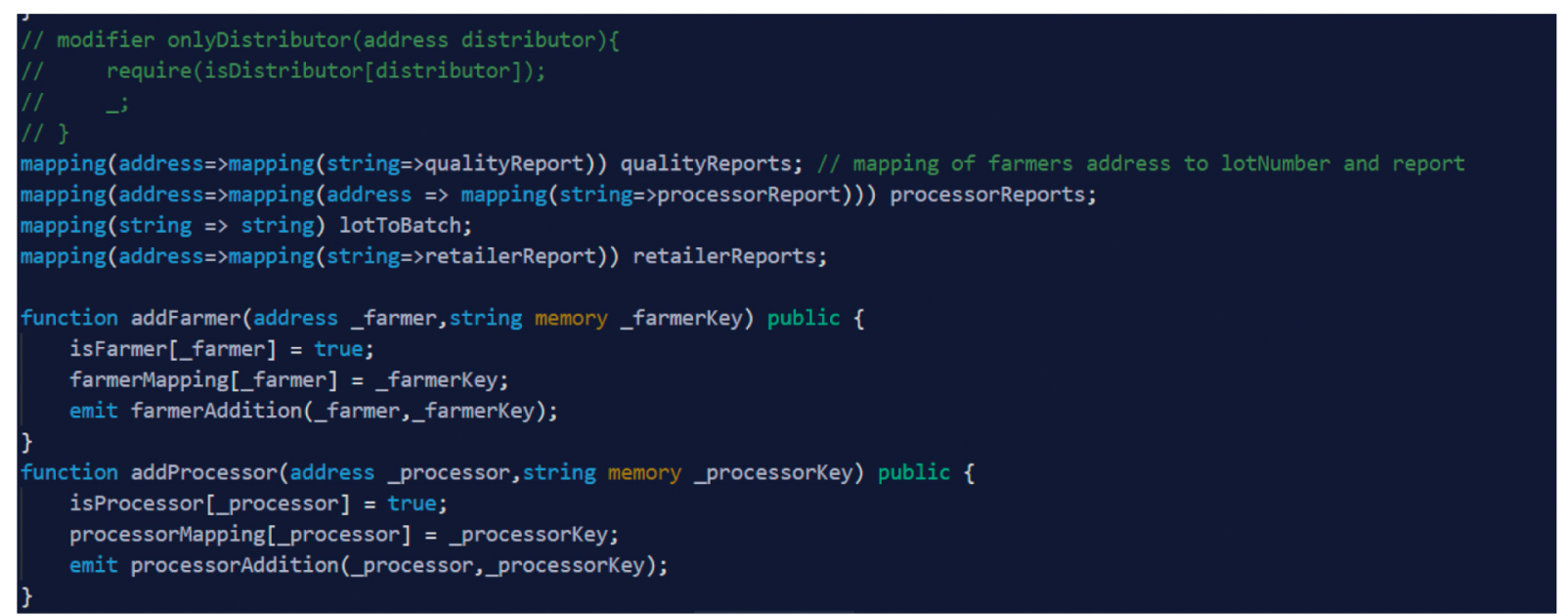

Figure 10: Part 3 of the smart contract.

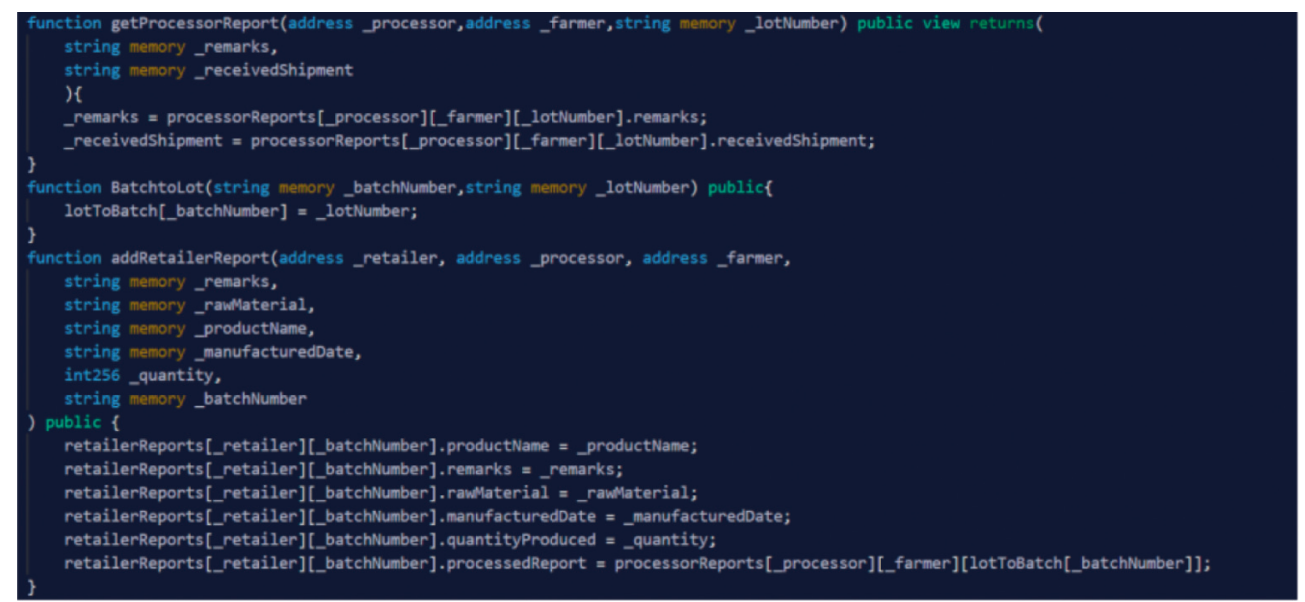

Figure 11: Part 4 of the smart contract.

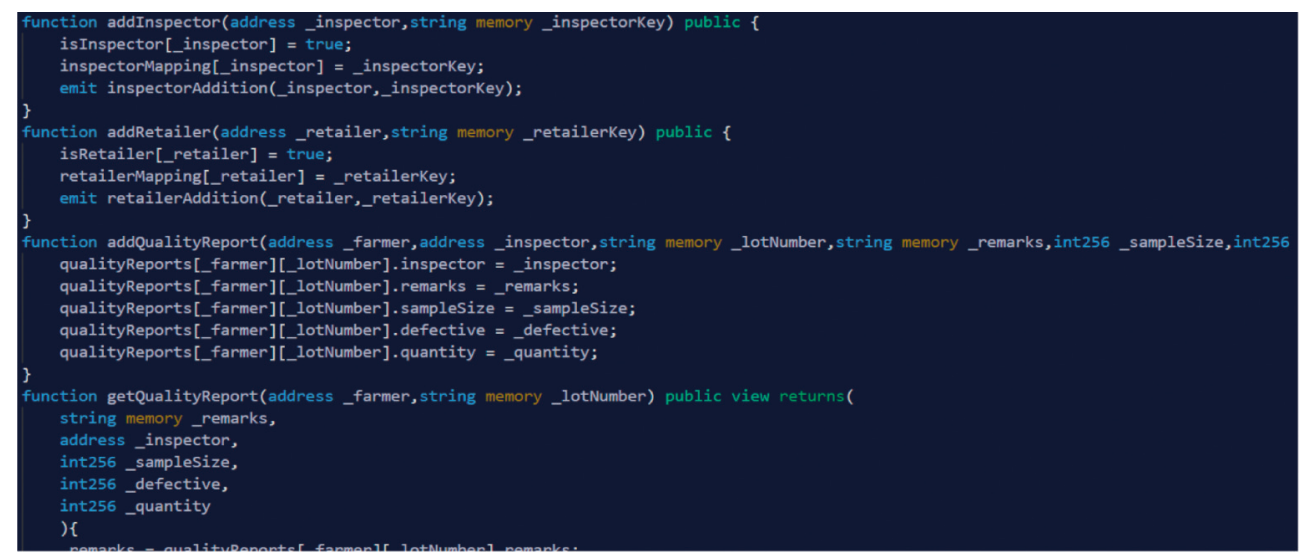

Figure 12: Part 5 of the smart contract.

While checking the issues in the deployed smart contract, we have then complied it with the available Ethereum test network and this can be seen in Figure 13.
Figure 14 shows the real-time working mechanism of the deployed smart contract where all the defined instances of the smart contracts are being called and executed. 


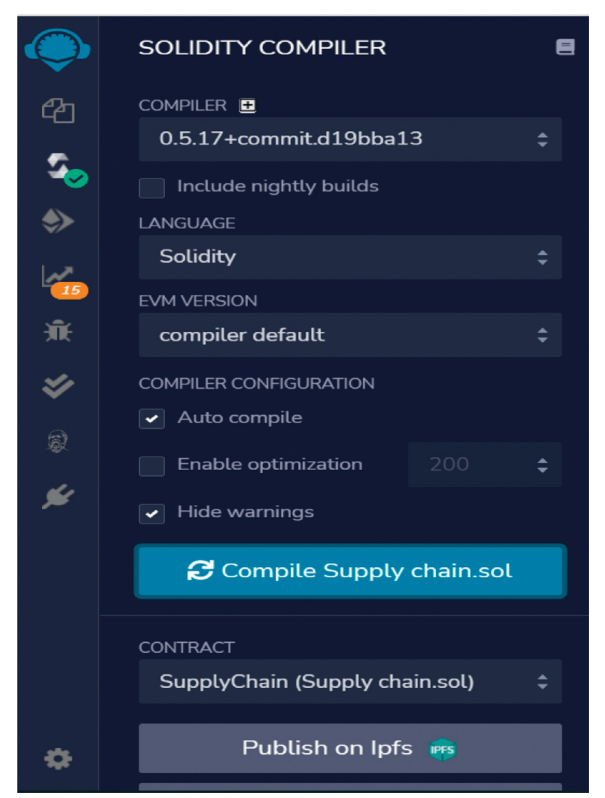

Figure 13: Part 6 of the smart contract.

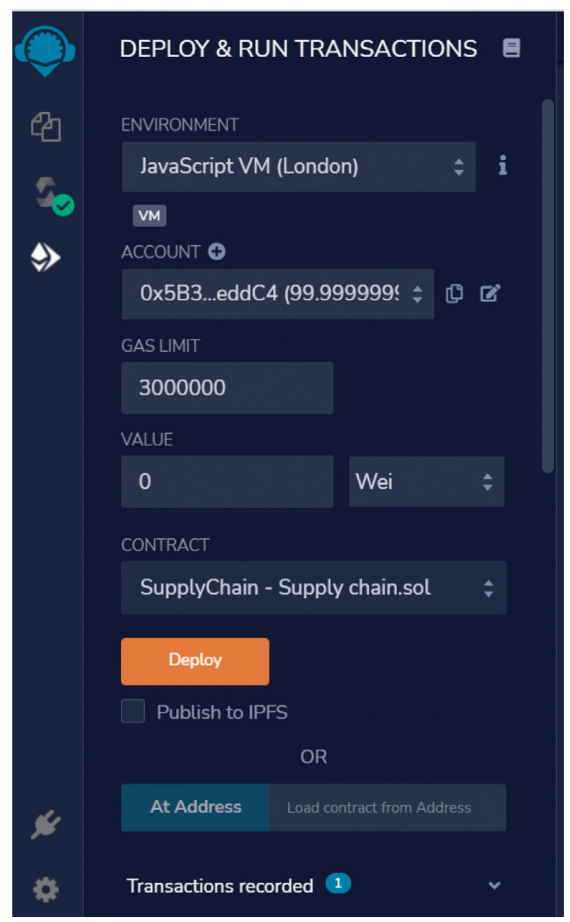

Figure 14: Part 7 of the smart contract. 


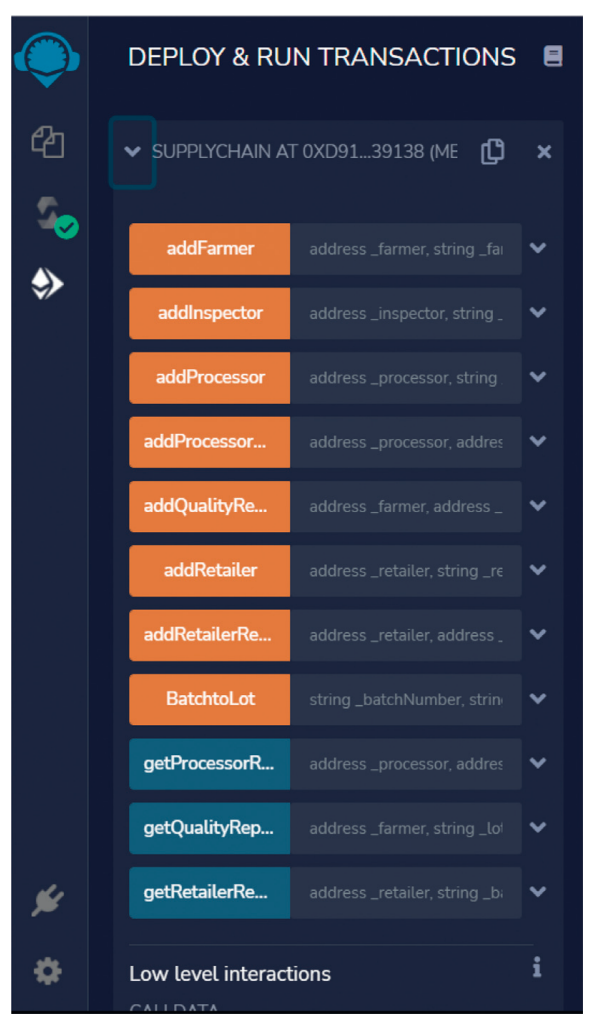

Figure 15: Part 8 of the smart contract.

The last part of the validation section is Figure 15; this part shows all the sections, i.e., the components of the assumed blockchain-based agri-food supply chain system, and how this can be tested with the help of Ethereum test networks.

\section{Conclusion and Future Work}

Researchers are trying hard to develop such systems that can bring innovation in the current scenarios. Blockchain technology is one of the developing and emerging technologies nowadays as this technology is disrupting every field and also it can make a lot of revolutionary changes in the agriculture field by improving the supply chain and ensuring the integrity, security, and traceability of data. It has the potential to improve the country's economic situation by lowering corruption and improving producer and customer satisfaction. Blockchain establishes an efficient and transparent system by eliminating the middleman in supply chain management. In this paper, we introduce an advanced blockchain approach to enhance the traditional supply chain. For managing the whole supply chain efficiently, we use a multi-agent system with smart contracts because they eliminate intermediaries, allowing the circular economy market to thrive. Our methodology is automated; it can be used to optimize any supply chain, resulting in increased security and efficiency. Utilizing blockchain technology, we give robust security characteristics to the agriculture system. Origin of product can be verified, shipment of product can be monitored, and proof of all transactions can be saved with this model. Agents who verify that both parties are following the terms and conditions of smart contact are another novelty of this study. Fine or penalties are imposed if the agent detects that a participant does not fulfill the conditions. This makes our models more reliable and efficient compared to other models; furthermore it can also track and authenticate orders. Apart from that, we have developed a smart contract in solidity using Ethereum blockchain to validate our model. Researchers can test this kind of proof of concepts as well as model using hyper ledger fabric composer or multi-chain tools that are exclusively designed to work with the permissioned blockchain where all the entities are known. The article addresses two main research questions. We first examine some of the most important issues of the traditional supply chain ecosystem, and then we explore how blockchain technology can be used to resolve these issues. This was done by looking at published research articles in the field. Our second question required an analysis of the benefits of integrating blockchain technology with supply chains. In conjunction with Ethereum's blockchain and the proof of authority consensus algorithm, an interplanetary file system is used. In smart contracts, payments can be processed directly and without intermediaries, which improves performance. An overview of the proposed smart contract model is presented in this paper, together with entity-relationship diagrams, sequence diagrams, and practical implementations. With the immutable nature of block chain technology, trust, transparency, and security can be enhanced within the supply chain. It is possible to adapt this model to a wide variety of supply chains in various domains.

\section{Data Availability}

The data used to support the findings of this study are available from the corresponding author upon request.

\section{Conflicts of Interest}

The authors declare no conflicts of interest.

\section{Acknowledgments}

This research was supported by the Researchers Supporting Project Number (RSP2022R476), King Saud University, Riyadh, Saudi Arabia.

\section{References}

[1] S. Umamaheswari, S. Sreeram, N. Kritika, and D. R. Jyothi Prasanth, "BIoT: blockchain based IoT for agriculture," in Proceedings of the 2019 11th International Conference on Advanced Computing (ICoAC), pp. 324-327, IEEE, Chennai, India, 18 December 2019.

[2] J. Xu, S. Guo, D. Xie, and Y. Yan, "Blockchain: a new safeguard for agri-foods," Artificial Intelligence in Agriculture, vol. 4, pp. 153-161, 2020.

[3] J. Duan, C. Zhang, Y. Gong, S. Brown, and Z. Li, "A contentanalysis based literature review in blockchain adoption within food supply chain," International Journal of Environmental Research and Public Health, vol. 17, no. 5, p. 1784, 2020. 
[4] G. Mirabelli and V. Solina, "Blockchain and agricultural supply chains traceability: research trends and future challenges," Procedia Manufacturing, vol. 42, pp. 414-421, 2019.

[5] S. F. Wamba and M. M. Queiroz, "Blockchain in the operations and supply chain management: benefits, challenges and future research opportunities," International Journal of Information Management, vol. 52, no. xxxx, Article ID 102064, 2020.

[6] M. D. Borah, V. B. Naik, R. Patgiri, A. Bhargav, B. Phukan, and S. G. M. Basani, Supply Chain Management in Agriculture Using Blockchain and IoT, Springer, Singapore, 2020.

[7] P. Dutta, T.-M. Choi, S. Somani, and R. Butala, "Blockchain technology in supply chain operations: applications, challenges and research opportunities," Transportation Research Part E: Logistics and Transportation Review, July, vol. 142, , p. 102067, 2020.

[8] O. Bermeo-Almeida, M. Cardenas-Rodriguez, T. SamaniegoCobo, E. Ferruzola-Gómez, R. Cabezas-Cabezas, and W. Bazán-Vera, "Blockchain in agriculture: a systematic literature review," Communications in Computer and Information Science, vol. 883, pp. 44-56, 2018.

[9] M. Torky and A. E. Hassanein, "Integrating blockchain and the internet of things in precision agriculture: analysis, opportunities, and challenges," Computers and Electronics in Agriculture, vol. 178, no. April, p. 105476, 2020.

[10] K. Salah, N. Nizamuddin, R. Jayaraman, and M. Omar, "Blockchain-based soybean traceability in agricultural supply chain," IEEE Access, vol. 7, no. c, pp. 73295-73305, 2019.

[11] A. Vangala, A. K. Das, N. Kumar, and M. Alazab, "Smart secure sensing for IoT-based agriculture: blockchain perspective," IEEE Sensors Journal, vol. 21, no. 16, pp. 17591-17607, 2021.

[12] A. Shahid, A. Almogren, N. Javaid, F. A. Al-Zahrani, M. Zuair, and M. Alam, "Blockchain-based agri-food supply chain: a complete solution," IEEE Access, vol. 8, pp. 69230-69243, 2020.

[13] S. Madumidha, P. S. Ranjani, U. Vandhana, and B. Venmuhilan, "A theoretical implementation: agriculturefood supply chain management using blockchain technology," in Proceedings of the 2019 TEQIP III Sponsored International Conference on Microwave Integrated Circuits, Photonics and Wireless Networks (IMICPW), pp. 174-178, IEEE, Tiruchirappalli, India, 22 May 2019.

[14] M. A. Ferrag, L. Shu, X. Yang, A. Derhab, and L. Maglaras, "Security and privacy for green IoT-based agriculture: review, blockchain solutions, and challenges," IEEE Access, vol. 8, pp. 32031-32053, 2020.

[15] V. S. Yadav and A. R. Singh, "A systematic literature review of blockchain technology in agriculture," in Proceedings of the Int. Conf. Ind. Eng. Oper. Manag., pp. 973-981, 2019.

[16] H. Kim and M. Laskowski, Sustainable Solutions for Food, Farmers, and FinancingBlockchain Res. Inst., Canada, 2018, https://ssrn.com/abstract=3028164.

[17] J. Lin, A. Zhang, Z. Shen, and Y. Chai, "Blockchain and IoT based food traceability for smart agriculture," in Proceedings of the ACM Int. Conf. Proceeding Ser., pp. 1-6, ACM, Singapore, 28 July 2018.

[18] M. Creydt and M. Fischer, "Blockchain and more - algorithm driven food traceability," Food Control, vol. 105, pp. 45-51, 2019.

[19] S. H. Awan, S. Ahmed, A. Nawaz et al., "BlockChain with IoT, an emergent routing scheme for smart agriculture," International Journal of Advanced Computer Science and Applications, vol. 11, no. 4, pp. 420-429, 2020.
[20] G. Zhao, S. Liu, C. Lopez et al., "Blockchain technology in agri-food value chain management: a synthesis of applications, challenges and future research directions," Computers in Industry, vol. 109, pp. 83-99, 2019.

[21] M. H. Ronaghi, "A blockchain maturity model in agricultural supply chain," Information Processing in Agriculture, vol. 8, no. 3, pp. 398-408, 2021.

[22] A. Kamilaris, A. Fonts, and F. X. Prenafeta-Boldú, "The rise of blockchain technology in agriculture and food supply chains," Trends in Food Science \& Technology, vol. 91, pp. 640-652, 2019.

[23] F. Feng Tian, "A supply chain traceability system for food safety based on HACCP, blockchain \& Internet of things," in Proceedings of the 2017 International Conference on Service Systems and Service Management, 16-18 June 2017.

[24] M. P. Caro, M. S. Ali, M. Vecchio, and R. Giaffreda, "Blockchain-based traceability in Agri-Food supply chain management: a practical implementation," in Proceedings of the 2018 IoT Vertical and Topical Summit on Agriculture Tuscany (IOT Tuscany), pp. 1-4, IEEE, Tuscany, Italy, 8 May 2018.

[25] M. Kim, B. Hilton, Z. Burks, and J. Reyes, "Integrating blockchain, smart contract-tokens, and IoT to design a food traceability solution," in Proceedings of the 2018 IEEE 9th Annual Information Technology, Electronics and Mobile Communication Conference (IEMCON), vol. 1, pp. 335-340, Vancouver, BC, Canada, 1 November 2018.

[26] M. Shyamala Devi, R. Suguna, A. S. Joshi, and R. A. Bagate, Design of IoT Blockchain Based Smart Agriculture for Enlightening Safety and Security, Vol. 985, Springer, , Singapore, 2019.

[27] S. S. Kamble, A. Gunasekaran, and R. Sharma, "Modeling the blockchain enabled traceability in agriculture supply chain," International Journal of Information Management, vol. 52, pp. 101967-102016, November 2020.

[28] D. Bumblauskas, A. Mann, B. Dugan, and J. Rittmer, “A blockchain use case in food distribution: do you know where your food has been?" International Journal of Information Management, vol. 52, no. September, pp. 102008-102010, 2020.

[29] L. Hang, I. Ullah, and D.-H. Kim, "A secure fish farm platform based on blockchain for agriculture data integrity," Computers and Electronics in Agriculture, vol. 170, Article ID 105251, 2020.

[30] K. Demestichas, N. Peppes, T. Alexakis, and E. Adamopoulou, "Blockchain in Agriculture Traceability Systems: a Review Featured Application: the paper elaborates on the applicability of blockchain technology in traceability systems of agri-food products," Applied Sciences, vol. 10, 2020, http://www.mdpi. com/journal/applsci.

[31] A. Scuderi, V. Foti, and G. Timpanaro, "The supply chain value of pod and pgi food products through the application of blockchain," Qual. - Access to Success, vol. 20, no. S2, pp. 580-587, 2019.

[32] S. V. Akram, P. K. Malik, R. Singh, G. Anita, and S. Tanwar, "Adoption of blockchain technology in various realms: opportunities and challenges," Security and Privacy, vol. 3, no. 5, pp. 1-17, 2020.

[33] P. W. Khan, Y.-C. Byun, and N. Park, "IoT-blockchain enabled optimized provenance system for food industry 4.0 using advanced deep learning," Sensors, vol. 20, no. 10, pp. 2990-3024, 2020.

[34] B. M. A. L. Basnayake and C. Rajapakse, "A Blockchain-based decentralized system to ensure the transparency of organic 
food supply chain," in Proceedings of the 2019 International Research Conference on Smart Computing and Systems Engineering (SCSE), pp. 103-107, IEEE, Colombo, Sri Lanka, 28 March 2019.

[35] V. S. Yadav and A. R. Singh, "Use of blockchain to solve select issues of Indian farmers," in Proceedings of the 1St International Conference on Advances in Mechanical Engineering and Nanotechnology (Icamen 2019), vol. 2148, AIP, 3 September 2019.

[36] P. Patil, M. Sangeetha, and V. Bhaskar, "Blockchain for IoT access control, security and privacy: a review," no. 1815, , 2020.

[37] J. Taskinsoy, "Blockchain: an unorthodox solution to reduce global warming," SSRN Electronic Journal, pp. 1-14, 2019.

[38] U. Bodkhe, S. Tanwar, P. Bhattacharya, and N. Kumar, "Blockchain for precision irrigation: opportunities and challenges," Transactions on Emerging Telecommunications Technologies, pp. 1-30, 2020.

[39] V. S. Yadav, A. R. Singh, R. D. Raut, and U. H. Govindarajan, "Blockchain technology adoption barriers in the Indian agricultural supply chain: an integrated approach," Resources, Conservation and Recycling, vol. 161, no. April, Article ID 104877, 2020.

[40] R. Casado-Vara, J. Prieto, F. D. la Prieta, and J. M. Corchado, "How blockchain improves the supply chain: case study alimentary supply chain," Procedia Computer Science, vol. 134, pp. 393-398, 2018.

[41] F. Antonucci, S. Figorilli, C. Costa, F. Pallottino, L. Raso, and P. Menesatti, "A review on blockchain applications in the agri-food sector," Journal of the Science of Food and Agriculture, vol. 99, no. 14, pp. 6129-6138, 2019.

[42] G. Rathee, M. Balasaraswathi, K. P. Chandran, S. D. Gupta, and C. S. Boopathi, "A secure IoT sensors communication in industry 4.0 using blockchain technology," Journal of Ambient Intelligence and Humanized Computing, vol. 12, no. 1, 545 pages, 2020.

[43] O. Alfandi, S. Khanji, L. Ahmad, and A. Khattak, "A survey on boosting IoT security and privacy throuagh blockchain Exploration , requirements, and open issues," Cluster Computing, vol. 24, no. 1, pp. 37-55, 2020.

[44] L. I. Frameworks, "PoAh: a novel consensus algorithm for fast scalable private blockchain for PoAh: a novel consensus algorithm for fast scalable private blockchain for large-scale IoT frameworks," 2020, https://arxiv.org/abs/2001.07297.

[45] S. Homayoun, A. Dehghantanha, R. M. Parizi, and K.-K. R. Choo, "A blockchain-based framework for detecting malicious mobile applications in app stores," in Proceedings of the 2019 IEEE Canadian Conference of Electrical and Computer Engineering (CCECE), no. Ccece, 5 May 2019.

[46] R. Xu, S. Y. Nikouei, D. Nagothu, A. Fitwi, and Y. Chen, "BlendSPS: a BLockchain-ENabled decentralized smart public safety system,” Smart Cities, vol. 3, no. 3, pp. 928-951, 2020. 